\title{
Automation of Passive Processes-A Methodology Adapted to a Bioclimatic Architecture
}

\author{
Bruno Marques and Luís M. Pestana Baptista
}

\begin{abstract}
The ultimate goal of bioclimatic architecture is to promote a sustainable living model, taking advantage of natural resources. However, nowadays guaranteed comfort standards are insufficient to promote this architecture as a more valid model. Thus, a domotic system is introduced. The aim of this combination is to guarantee bioclimatic efficiency and constant comfort conditions. The system promotes passive bioclimatic processes, with constant control of all the parameters, as controlling the openings, the shades, etc. Through a central system, the processes and timings are more accurate to the real needs, without human supervision and freeing the user of complex daily tasks. In this paper, we present an introduction to our investigation, with two different case studies: Oporto city, Portugal and Bissau city, Guiné-Bissau. Focusing the automation of passive processes on thermal comfort, daily processes during the most significant annual climate extremes are presented, supported by tables describing how the system should react in different situations and climate conditions.
\end{abstract}

Index Terms-Automation of passive processes, bioclimatic architecture, domotics.

\section{INTRODUCTION}

In architecture, the ultimate goal of sustainability is an efficient growth and development by taking full advantage of the natural resources, without imposing or exhausting them, and establishing a symbiosis between human needs of housing and the maintenance of the natural surroundings. Thus, the bioclimatic project concerns several aspects, in which shape, orientation and the use of natural resources, like the Sun, are only a part.

Currently, a major factor in the promotion and implementation of this architecture lies in the pursuit of energy efficiency. However, the response of bioclimatic models to the instant needs is often less than expected, in relation to what is guaranteed by the common, but unsustainable, architectural models.

Nowadays, architecture intends to respond to the needs and expectations of users. From the standpoint of the general user, the priority should be to ensure optimal housing comfort and functionality conditions, and, only then, efficiency and sustainability.

Nevertheless, in a common architecture or even in a bioclimatic approach, the processes needed to achieve and maintain the desired comfort are very complex and involve an ongoing management of all conditions, requiring house administration learning. Thus, it is common the use of active systems, like air conditioning equipment's, with significant

Manuscript received June 27, 2012; revised December 25, 2012.

Bruno Marques is with the Centro de Estudos Africanos da Universidade do Porto, Portugal (e-mail: arqbrunomarques@gmail.com). energy costs and inadequate thermal needs, causing the devaluation of the bioclimatic models, in relation to cheaper comfort / energy efficient architectural solutions.

Therefore, we believe that in the development of the bioclimatic architecture it is necessary to update the standards of comfort. To this goal, we propose the conjugation of an automated system, specially intended to guarantee a more efficient bioclimatic behavior. The execution of the necessary passive processes is accomplished, ensuring constant thermal comfort conditions and adapting the bioclimatic architecture to the current lifestyles, promoting it as a better constructive and philosophical model, whilst freeing the user of complex house management tasks.

\section{DOMOTICS}

The sustainability and bioclimatic architecture approach always has to consider the society where it is carried out. In fact, two different development concepts have been used over the centuries: the Western evolutionary concept and the Eastern one. The first one is based on energy demand and consumption, on mechanical and scientific explanation, and geared toward high-tech solutions. The second one seeks closeness to nature and to simpler solutions, exulting the mystical and spiritual, making use of Low-tech solutions.

Our approach aims to combine the Western mechanistic solutions with the Eastern mysticism. Thus, the bioclimatic architecture should explore the concepts associated to different notions of sustainability, to local building and construction concerns, to house management and climate processes, and adapt the knowledge to current live styles, becoming an improvement of local practices, rather than an imported movement

It is in this context that we introduce Domotics, a science in which there have been recent major investments and developments. Inherently related to architecture, to its concepts and ways of living, it assumes the central role of union and interaction of all the elements in our approach. Thus, based on an extended analysis of architectural components and their different processes, intentions and circumstances, a model of automation of the passive processes is proposed. According to the occupation of the different house compartments, time of the day, daily tasks, needed resources, etc, the goal is to monitor all internal and external conditions, such as temperature, humidity, solar radiation, wind speed, etc, and automatically ensure the correct passive processes.

Through the use of technology, better thermal performance, bioclimatic and health conditions are ensured. More efficiency and less time consuming, the house management is 
ensured, freeing the user to simply enjoy it. Moreover, the system allows a proper house management by those not familiar with local conditions. Throughout an intuitive process, it becomes possible to manage and understand the climate dynamics processes, ensuring comfort, without undergoing through long learning processes.

Apart from the advantages in the house daily management, it is also a science that monitors social trends and concerns. Some studies show that currently in Europe, about $20 \%$ of the population already has some kind of special disability, with a strong tendency to increase to $30 \%$ in the next century [1]. Being a factor of growing concern, as it is showed by 2012 European Year of Active Ageing, domotics systems have been proposed, specially focusing this area. Thus, by eliminating housing barriers, domotics can play an important social and democratic role, aiming to improve comfort and living conditions to all citizens, making the architecture more inclusive.

Our proposed methodology aims to address the main issues relating to thermal comfort. The principles of Fanger/ASHRAE [2] basic equation were adopted, focusing the passive internal processes on monitoring the indoor air temperature, air humidity, mean radiant temperature and air speed. The studies following Fanger's formula [3], [4] were also considered, as well as the characteristics and bioclimatic architecture performance issues. Lastly, the evaluation and determination of the correct parameters and values is subject to the relationship between indoor / outdoor conditions, occupation timing and activities. The often contradictory needs between thermal behavior, visual comfort and natural lighting were also taken onto account.

\section{CASE STUdies}

Two case studies are presented with distinct climate, social and cultural habits, showing that the carried out methodology has a wide adaptability.

Our first case is a representative European reality, a bioclimatic house located in Oporto, Portugal.

Oporto has a favorable climate, with a constant influence of the Atlantic Ocean that assures a good thermal balance. Thus, during an annual period, the maintenance of thermal comfort may imply the need to achieve and maintain higher internal environmental values (winter) or, on the other hand, to avoid unwanted heat gains (summer).

Through the recourse to a reliable source of climatic conditions registration [5], considering the hourly variation of the environmental conditions, we can determine four distinct daily cycles, either on the influence of external temperature, humidity, wind and mean radiant temperature, on the role of the different compartments, on the house thermal behavior during the day or relative to the habits of occupancy of the dwelling.

The night sleep cycle in winter is when the largest heat losses take part. In this case, the system must provide the necessary insulation elements for thermal comfort maintenance (Table I). During the summer, this cycle is intended to recover the conditions for the heat stage. To this purpose, the system promotes crossed night ventilation, to cool the materials (Table II).

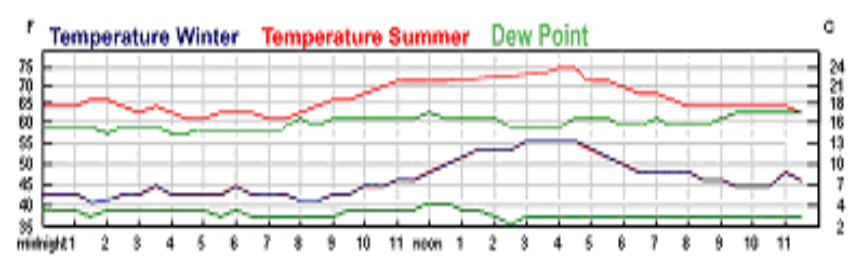

Fig. 1. Thermal daily evolution during a common winter (January) and summer (August) day, in Oporto.

TABLE I: PoRTo, Winter Night CyCle, BetweEn 23:00H AND 06:00H.

\begin{tabular}{l|l|l}
\hline $\begin{array}{l}\text { Compartments } \\
\text { with Internal } \\
\text { environment } \\
\text { parameters. }\end{array}$ & $\begin{array}{l}\text { Exterior } \\
\text { Environment }\end{array}$ & System Processes \\
\hline $\begin{array}{l}\text { Occupied } \\
19^{\circ} \mathrm{C}-22^{\circ} \mathrm{C} \\
35-60 \% \mathrm{HR}\end{array}$ & $86-81 \% \mathrm{HR}$ & $\begin{array}{l}\text { Metabolism to maintain high } \\
\text { temperatures. } \\
\text { Control of humidity through } \\
\text { internal vents functioning at } \\
\text { low-speed - unilateral ventilation. }\end{array}$ \\
\hline
\end{tabular}

TABLE II: PORTO, SuMMER Night CyCLE, BeTWEen 23:00H AND 06:00H.

\begin{tabular}{|c|c|c|}
\hline $\begin{array}{l}\text { Occupied } \\
20^{\circ} \mathrm{C}-22^{\circ} \mathrm{C} \\
35-45 \% \mathrm{HR}\end{array}$ & $\begin{array}{l}18^{\circ} \mathrm{C}-16^{\circ} \mathrm{C} \\
88-83 \% \mathrm{HR}\end{array}$ & $\begin{array}{l}\text { Air ventilation processes, to control } \\
\text { the moist - use of louvers, allowing } \\
\text { internal low-speeds. } \\
\text { Reduce the sensation of heat - } \\
\text { process of cross ventilation, with a } \\
\text { maximum air speed of } 0.5 \mathrm{~m} / \mathrm{s} \text { up to } \\
0.7 \mathrm{~m} / \mathrm{s} \text {. }\end{array}$ \\
\hline
\end{tabular}

The waking up cycle comprises the moment of waking and early morning activities. The reduction of thermal shocks and the relationship between indoor and outdoor environments are implied. In the cold season, a particular attention should be given to thermal losses in those processes, ensuring the capture of solar gains for thermal compensation. In summer, concerns about thermal behavior in this cycle are relatively small, mainly focused on avoiding direct solar radiation on the thermal mass elements, allowing to concentrate on the psychological needs.

The day cycle has more influence on the behavior of the bioclimatic house. In winter, it represents the solar gain period, which will be used for house heating. Thus, the system should expose the thermal mass elements to direct radiation (Table III). In the summer, the objective is to isolate the elements of unwanted heat gains, through the placement of shading on the spans. Ventilation processes may be used to achieve a good comfort feeling (Table IV).

\begin{tabular}{l|l|l}
\multicolumn{2}{l}{ TABLE III: PORTO, WINTER DAy CYCLE, BETWEEN 11:00H AND 18:00H. } \\
\hline $\begin{array}{l}\text { Occupied } \\
21^{\circ} \mathrm{C}-23^{\circ} \mathrm{C}\end{array}$ & $\begin{array}{l}\text { Constant relationship with the } \\
\text { environment - controlled exposure } \\
\text { of the spans, directing heat radiation } \\
\text { gains by solar radiation to thermal }\end{array}$ \\
& $\begin{array}{l}76-51-62 \% \mathrm{HR} \\
\text { HR }\end{array}$ & $\begin{array}{l}\text { As the attractiveness of the external } \\
\text { environment - make larger or smaller } \\
\text { values of isolation, considering the } \\
\text { needs of natural lighting. }\end{array}$ \\
&
\end{tabular}


TABLE IV: PORTO, SUMMER DAY CYCLE, BETWEEN 11:00H AND 18:00H.

\begin{tabular}{l|l|l}
\hline Occupied & & $\begin{array}{l}\text { Constant relationship with the } \\
\text { environment }- \text { in the controlled } \\
\text { exposure of the spans, protect of }\end{array}$ \\
$55-80 \% \mathrm{HR}-24^{\circ} \mathrm{C}$ & $22-24-21^{\circ} \mathrm{C}$ \\
$69-44-68 \%$ & HR & $\begin{array}{l}\text { heat gains, placing outside elements } \\
\text { for shading and avoiding direct } \\
\text { sunlight to thermal mass elements. } \\
\text { Cross ventilation of the } \\
\text { compartments with slightly } \\
\text { noticeable air-speed. }\end{array}$ \\
\hline
\end{tabular}

The end of the day cycle is marked by the relationship between thermal environment and thermal behavior needs. In winter, this relationship takes place at sun set, making visual and psychological connection essential. In this case, the management system provides a gradually increasing thermal insulation, while focusing on the comfort aspects of the internal environment. After the isolation takes place, the system takes advantage of the heat released by the elements and also prevents its dissipation. In summer, this interior / external relationship is longer, achieved through the thermal equilibrium between the environments. During this cycle, there may be an effective opening of the windows, allowing a greater relationship, while providing ventilation of the interior thermal load elements. When the internal temperature values are reduced, the system promotes the housing closure, maintaining an essential heat capacity.

Our second case is located in the city of Bissau, Guinea-Bissau.

In this city, the climate is characterized by intense heat and humidity, with constant high temperatures and moderate wind. The tropical climate is marked by two extremes, the annual rainy season (May to October) and the dry season (November to April). During rainfall season, the average temperatures are balanced, although naturally high, but often with relative humidity above $90 \%$. On the other hand, the dry season has a low relative humidity, with daily high thermal variations. In this case, the passive processes are mainly focused on the ventilation and humidity control, and occasionally in the control of natural lighting, shadings or to achieve some heat gains.

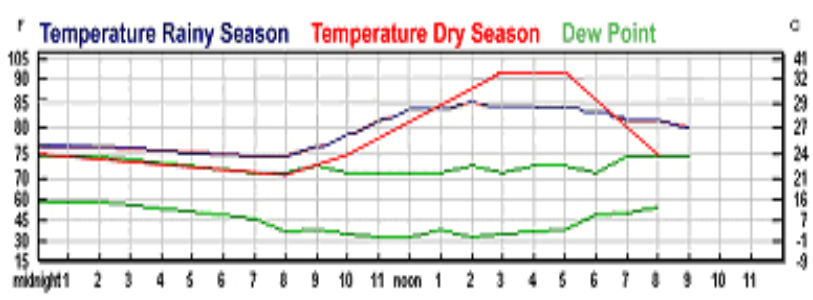

Fig. 2. Thermal daily evolution in the rainy season (September) and in the dry season (February), in Bissau.

The night cycle, during the rainy season, is characterized by equilibrium of temperatures, but with high humidity. Thus it is essential to constantly ensure the parameters of thermal comfort, particularly in the rooms. The system may then proceed to the thermal insulation. By keeping the internal temperature slightly rose, it is possible to achieve a balanced relative humidity. The internal ventilation is also essential for this purpose (Table V). During the dry period, the main goal is to dissipate the heat accumulated during the day by a process of cross ventilation, always with due regard to maintain a stable thermal load (Table VI).
TABLE V: Bissau, RAINy SEAson, Night CyCLE, BeTweEn 23:00H AND 06:00H.

\begin{tabular}{l|l|l}
\hline $\begin{array}{l}\text { Occupied } \\
26^{\circ} \mathrm{C}\end{array}$ & $\begin{array}{l}\text { The indoor air ventilation takes on } \\
\text { vital importance }- \text { it's imperative to } \\
55-75 \% \mathrm{HR}\end{array}$ & $\begin{array}{l}25^{\circ} \mathrm{C}-24^{\circ} \mathrm{C} \\
90 \% \mathrm{HR}\end{array}$ \\
& $\begin{array}{l}\text { maintain humidity within the } \\
\text { comfort parameters. } \\
\text { If needed, raise the temperature to } \\
\text { reduce moisture - use internal } \\
\text { unilateral ventilation process. }\end{array}$ \\
\hline
\end{tabular}

TABLE VI: BISSAU, DRY SEASON, Night CyCLE, BETWEEN 23:00H AND 06:00H.

\begin{tabular}{l|l|l}
\hline $\begin{array}{l}\text { Occupied } \\
24^{\circ} \mathrm{C}-26^{\circ} \mathrm{C}\end{array}$ & $\begin{array}{l}\text { Maintenance of the thermal comfort } \\
\text { parameters. } \\
35-55 \% \mathrm{HR}\end{array}$ & $\begin{array}{l}{ }^{\circ} \mathrm{C}-21^{\circ} \mathrm{C} \\
\text { Control the humidity - use of } \\
\text { internal louvers at low-speed. } \\
\text { Reduce the sensation of heat - } \\
\end{array}$ \\
& $\begin{array}{l}\text { process of cross ventilation, with a } \\
\text { maximum air speed of } 0.5 \mathrm{~m} / \mathrm{s} \text { up to } \\
0.7 \mathrm{~m} / \mathrm{s} .\end{array}$ \\
\hline
\end{tabular}

The waking up cycle requires the maintenance of stable conditions between internal and external environments. In this process, the system takes advantage of solar radiation, to ensure the heat load necessary to maintain the relative humidity. Close to the end of the cycle, it should be possible to vent directly from the external environment. In the dry season, the cycle is marked by the relationship between the environments, always avoiding direct sunlight on the materials. The ventilation processes should be performed until external environmental conditions are harmful.

TABLE VII: BISSAU, RAINY SEASON, DAY CYCLE, BETWEEN 11:00H AND

\begin{tabular}{l|l|l}
\hline $\begin{array}{l}\text { Occupied } \\
26^{\circ} \mathrm{C}-29^{\circ} \mathrm{C}\end{array}$ & $\begin{array}{l}\text { Apply the elements of climate } \\
\text { protection. } \\
40-70 \% \mathrm{HR}\end{array}$ & $\begin{array}{l}\text { Controlled ventilation - the gains are } \\
70-65 \% \mathrm{HR}\end{array}$ \\
& $\begin{array}{l}\text { balanced by maintaining air } \\
\text { velocities slightly perceptible for a } \\
\text { cooling sensation. } \\
\text { Avoid blowing hot air in the peak } \\
\text { hours - suspend ventilation } \\
\text { processes or ensure the heat } \\
\text { extraction in this process. }\end{array}$ \\
\hline
\end{tabular}

TABLE VIII: BISSAU, DRY SEASON, DAy CYCLE, BETWEEN 11:00H AND

\begin{tabular}{l|l|l}
\hline \multicolumn{2}{|c}{$18: 00 \mathrm{H}}$. \\
$26^{\circ} \mathrm{C}-29^{\circ} \mathrm{C}$ & $\begin{array}{l}\text { Constant relationship with the } \\
\text { environment - drive the solar } \\
\text { radiation to the outside or to elements } \\
35-45 \% \mathrm{HR}\end{array}$ & $\begin{array}{l}\mathrm{HR}-35-32^{\circ} \mathrm{C} \\
\text { without thermal mass. } \\
\text { Place elements of shading over the } \\
\text { windows and external mass elements. } \\
\text { Cross ventilation of the } \\
\text { compartments, with noticeable } \\
\text { speed. Ventilate through the areas } \\
\text { with shadow, wetlands or operate the } \\
\text { irrigation system. }\end{array}$ \\
\hline
\end{tabular}

The day cycle, in the rainy season, should pay special attention to the protection of external environmental factors, particularly rainfall. The system should use protective elements on the facades, pushing the water away from the house. Thus, it is possible to vent the interior with a more balanced humidity (Table VII). During dry period, the system should apply a maximum insulation, preventing harmful heat gains. In occupied compartments constant ventilation may be 
required, through the opening of windows, preferably by spare zones or humid environments (Table VIII).

At the end of the day cycle, the system should isolate the home and stop the processes of external ventilation. With the raise of relative humidity, it is necessary to promote an increase of internal temperature in order to achieve lower moisture. In the opposite climate, the insurance of the thermal insulation is to be maintained while environmental conditions are detrimental. After this point, it is possible to provide a wider relationship between the environments, opening up the windows. In addition to psychological gains, ventilation of the thermal mass of elements will also be beneficial by cooling the house.

\section{CONCLUSION}

When adapting local knowledge and improving local practices, by the use of bioclimatic architecture and domotics, a better house management and the execution of the passive processes are achieved, guaranteeing a good thermal performance and freeing the users of these tasks.

Although only extreme annual daily climate examples were presented, the validity of the methodology is clear, whether in another climate season or even in a totally different climatic context.

\section{REFERENCES}

[1] F. J. L. Nuno, "Promise, cited from: COSTA, in mobilidade virtual," Dissertation Submitted to Achieve the Master Degree in Computer an Electronic Engineering, FEUP, pp. 22, 1998.

[2] BSR/ASHRAE Standard 55P, Thermal Environmental Conditions for Human Occupancy, Atlanta, 2003.
[3] K. E. Charles, Fanger's Thermal Comfort and Draught Models, Otava: National Research Council Canada, 2003.

[4] E. E. H. Halawa and C. J. Marquand, A Method of Implementing FANGER/ASHRAE Comfort Criteria in Air Conditioning Controls, Telaah, Jilid XVI, No $1,1995$.

[5] Weather Underground-Global Climate Data. [Online]. Available: $\mathrm{http}: / / \mathrm{www}$. wunderground.com.

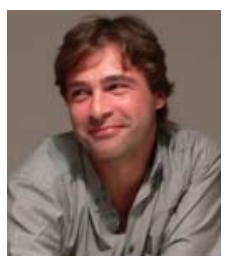

Bruno Gomes Marques was born in Espinho, Portugal 1973. PhD in Civil Engineering at Faculty of Engineering University of Oporto,Portugal, 2011. PhD in Architecture at Valladolid University, Spain, 2010. Master degree in Urban Planning at Faculty of Architecture, University of Oporto, Portugal. Associate Regent Professor, Researcher at Master degree in Architecture and Urbanism, at Faculty of Architecture and Arts, University Lusíada Porto. Researcher and coordinator of NGO CEAUP for the area of Sustained Economic Development in Africa. Issues and projects of applied research. applied research in Africa eco-development (architecture and urbanism), Developed research in the field of Civil Engineering, within a multidiciplinary research team, with the title: Energy Efficiency in Residential Buildings - From Theory to Practice. Application of the Principles of Bioclimatic Architecture to Practice at Dept. of Civil Engineering, Faculty of Engineering University of Oporto.

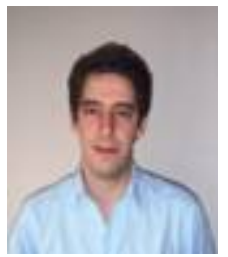

Luís M. Pestana Baptista was born in Oporto, 1985 Master degree in architecture at Universidade Lusíada, Oporto, Portugal, 2012. During and after academic studies, has collaborated in architecture projects. Recently, has been part of the Felgueiras's district and local urban mobility plan, working with DHV Consultancy and engineering. Has also worked in the public buildings accessibility plan in Felgueiras, along with architect Pedro Pimentel. During the last few years has been dedicated to research bioclimatic architecture and the possibilities of a domotics interaction. 